EGU21-5271, updated on 04 May 2021

https://doi.org/10.5194/egusphere-egu21-5271

EGU General Assembly 2021

(c) Author(s) 2021. This work is distributed under

the Creative Commons Attribution 4.0 License.

\title{
How does the Arctic affect North Atlantic climate? Fresh perspectives on a long-standing question.
}

\author{
Marilena Oltmanns ${ }^{1}$, N. Penny Holliday ${ }^{1}$, James Screen ${ }^{2}$, D. Gwyn Evans ${ }^{1}$, Simon A. Josey ${ }^{1}$, Ben \\ Moat $^{1}$, Johannes Karstensen ${ }^{3}$, and G. W. Kent Moore ${ }^{4}$ \\ ${ }^{1}$ National Oceanography Centre, Marine Physics and Ocean Climate, United Kingdom of Great Britain - England, Scotland, \\ Wales (marilena.oltmanns@noc.ac.uk) \\ ${ }^{2}$ University of Exeter, Mathematics, United Kingdom of Great Britain - England, Scotland, Wales \\ ${ }^{3}$ GEOMAR Helmholtz Centre for Ocean Research Kiel, Physical Oceanography, Germany \\ ${ }^{4}$ University of Toronto, Department of Physics, Canada
}

Recent decades have been characterised by amplified Arctic warming and increased occurrence of extreme weather events in the North Atlantic region. While earlier studies noticed statistical links between high-latitude warming and mid-latitude weather extremes, the underlying dynamical connections remained elusive. Combining different data products, I will demonstrate a new mechanism linking Arctic ice losses with cold anomalies and storms in the subpolar region in winter, and with heat waves and droughts over Europe summer. Considering feedbacks of the identified mechanism on the Arctic Ocean circulation, I will further present new support for the potential of Arctic warming to trigger a rapid change in climate. 